\title{
Study on Comprehensive Evaluation Model of Commercial Housing Price-Rationalization
}

\author{
Yifei Lai, Yuanxin Wei, Haiyun Luo
}

School of Economics and Management, Wuhan University, Wuhan, China.

Email:1yf37319@163.com

Received July $7^{\text {th }}, 2010$; revised August $10^{\text {th }}, 2010$; accepted September $12^{\text {th }}, 2010$.

\begin{abstract}
In recent years, the prices of city commercial housing are soaring, causing wide attention of public and fierce discussion about whether it is reasonable for the housing prices in China. This paper attempts to establish a method to measure housing price-rationalization. Firstly, the paper establishes rationalization evaluation system of housing price from commercial housing price formation, residents' endurance and coordination parity system. Then it selects an appropriate standard ways to build affordable housing product evaluation criteria.
\end{abstract}

Keywords: Commercial Housing, Rationalization of Price, Comprehensive Evaluation

\section{Introduction}

Housing Industry is an important industry to promote economy and social development. In recent years, the price of commercial housing is soaring. Currently, there is a fierce controversy about whether the commercial housing prices are rational. Therefore, this paper attempts to establish a measurement system to determine the rationality of housing price.

Most rational studies about commercial housing mainly focus on two aspects: Firstly, according to bubble of the real estate, we can judge whether the commercial housing price is reasonable. Secondly, by choosing single or multiple indexes, we can study rationality of commercial housing price. Recently, the study about an index system mainly centers on analysis of single or many indexes. In a multiple criteria system, some indexes are chose to measure the rationality. There are two kinds: one results from formation of housing price, establishment, bearing capability of residents, revenue and so on[1]; another results from aspects of demand and requirement, factors of influencing price, and demand and requirement $[2,3]$.

This paper is based on generalizing two kind of index evaluation method to establish an integrated evaluation model.

\section{Index System and Determine the Weight-AHP}

AHP (Analytical Hierarchy Process) is proposed by
American operations researcher Satty. T. L in 1970s. AHP basic steps are as follows:

\subsection{Construction of Analytic Hierarchy}

Firstly, we should decompose the complex problem into single element. These elements should be divided into several groups to form different levels according to the relationship between these elements. At the top level there is usually only one element, which is the general target of the problem or the desired results. The middle layer is always the criteria layer, and the lowest layer includes the decision-making program. The dominant relationship between the elements in different levels is not necessarily complete.

According to the relevant information and practical experience, author has selected some representative and comprehensive indexes which can reflect each side of the system, to finalize the evaluation index system of the commercial housing price rationality.

1) Target layer $A$

The overall objective is whether the commercial housing price is rational.

2) Criteria layer $B$

Criteria layer includes three parts: the formation of housing price, the affordability of residents and coordination of parity price.

3) Index layer

It includes: Ratio of commercial housing, Homeownership rate, Housing Vacancy Rate, Ratio of Housing Price 
to Income, Housing expenditure ratio, Ratio of housing price growth rate to it of income, Ratio of rent to housing price, Ratio of housing price growth rate to it of retail price, Ratio of housing price growth rate to it of GDP. (Figure 1)

The ideal range of the indexes is shown in Table 1.

\subsection{Structure the Judgment Matrix}

After the establishment of the hierarchy, the relationships of the elements between the upper and lower layers were determined. In this step, decision-makers should repeatedly answer: For the guidelines $B_{k}$, which element is more important between $\mathrm{C}_{\mathrm{i}}$ and $\mathrm{C}_{\mathrm{j}}$, and gives this a certain mark. The formula for assignment can be directly given by the decision-makers, or by analysis through some kind of received advice. Generally, the expert familiar with the matter can give the weight according to the 1-9 scaling law. (Table 2)

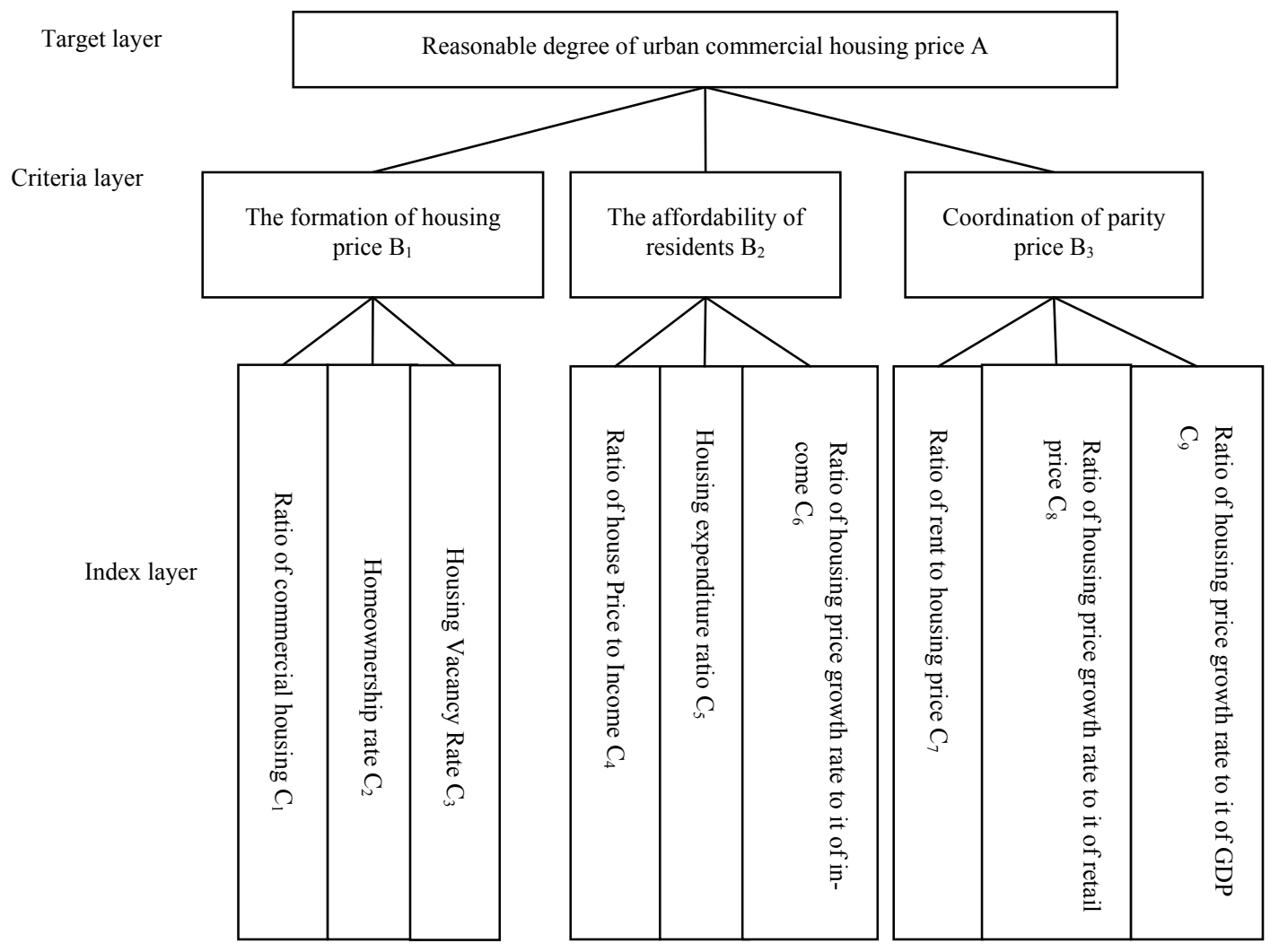

Figure 1. Rationality index system of chinese urban commodity housing.

Table 1. The ideal and rational ranges of the indexes in Figure 1.

\begin{tabular}{lccc}
\hline \multicolumn{1}{c}{ Index } & Ideal range & Max & Min \\
\hline Ratio of commercial housing & $90 \% \sim 100 \%$ & $100 \%$ & $45 \%$ \\
Homeownership rate & $60 \% \sim 70 \%$ & $100 \%$ & $40 \%$ \\
Housing Vacancy Rate & $15 \% \sim 30 \%$ & $4.5 \%$ & 2 \\
Ratio of house Price to Income & $4 \sim 7$ & 10.5 & $10 \%$ \\
Housing expenditure ratio & $20 \% \sim 30 \%$ & 1.8 & 50 \\
Ratio of housing price growth rate to it of income & $0 \sim 1.2$ & 50 & 2.25 \\
Ratio of rent to housing price & $100 \sim 200$ & $1.2 \sim 1.5$ & 2 \\
Ratio of housing price growth rate to it of retail price & $0 \sim 1.3$ & 0.6 \\
Ratio of housing price growth rate to it of GDP & & 0 \\
\hline
\end{tabular}


Table 2. 1-9 scaling law.

\begin{tabular}{lc}
\hline \multicolumn{1}{c}{ Significance level } & $C_{\mathrm{ij}}$ \\
\hline Concern the previous layer, $C_{\mathrm{i}}$ and $\mathrm{C}_{\mathrm{j}}$ are equally important & 1 \\
Concern the previous layer, $\mathrm{C}_{\mathrm{i}}$ is slightly important than $\mathrm{C}_{\mathrm{j}}$ & 3 \\
Concern the previous layer, $\mathrm{C}_{\mathrm{i}}$ is obviously important than $\mathrm{C}_{\mathrm{j}}$ & 5 \\
Concern the previous layer, $\mathrm{C}_{\mathrm{i}}$ is strongly important than $\mathrm{C}_{\mathrm{j}}$ & 7 \\
Concern the previous layer, $\mathrm{C}_{\mathrm{i}}$ is extremely important than $\mathrm{C}_{\mathrm{j}}$ & 9 \\
Concern the previous layer, $\mathrm{C}_{\mathrm{i}}$ is slightly less important than $\mathrm{C}_{\mathrm{j}}$ & $1 / 3$ \\
Concern the previous layer, $\mathrm{C}_{\mathrm{i}}$ is obviously less important than $\mathrm{C}_{\mathrm{j}}$ & $1 / 5$ \\
Concern the previous layer, $\mathrm{C}_{\mathrm{i}}$ is strongly less important than $\mathrm{C}_{\mathrm{j}}$ & $1 / 7$ \\
Concern the previous layer, $\mathrm{C}_{\mathrm{i}}$ is extremely less important than $\mathrm{C}_{\mathrm{j}}$ & $1 / 9$ \\
The important scale between the two adjacent judgments & $2,4,6,8,1 / 2,1 / 4,1 / 6,1 / 8$ \\
\hline
\end{tabular}

Structure the comparison matrix $C_{n} \times{ }_{n}$ :

$$
C_{n \times n}=\left(\begin{array}{cccc}
C_{11} & C_{12} & \cdots \cdots & C_{1 n} \\
C_{21} & C_{22} & \cdots \cdots & C_{2 n} \\
\cdots & \cdots & \cdots & \cdots \\
C_{n 1} & C_{n 2} & \cdots \cdots & C_{n n}
\end{array}\right)
$$

\subsection{Single-Level Sorting and Consistency Check}

In theory, single-level sorting can come down to the calculation of the characteristic roots and eigenvector of the judgment matrix C. $C W=\lambda_{\max } W$, here, $\lambda_{\max }$ is the maximum characteristic root, and $W$ is the corresponding normalized vector to $\lambda_{\max } W_{i}$ is the component of $W$, it is the weight.

We choose square-root method to calculate $\lambda_{\max }$ and $W$. Steps are as follows:

1) Calculate $M_{i}$, the product of each row elements of matrix;

$$
M_{i}=\prod_{j=1}^{n} c_{i j}, \quad i=1,2, \cdots, n
$$

2) Calculate $\bar{W}_{i}$, the n-th root of $M_{i}$;

$$
\bar{W}_{i}=\sqrt[n]{M_{i}}
$$

3) Normalization of the vector $\bar{W}=\left[\bar{W}_{1}, \bar{W}_{2}, \cdots, \bar{W}_{n}\right]^{T}$;

$$
\bar{W}_{i}=\frac{\bar{W}_{i}}{\sum_{j=1}^{n} \bar{W}_{j}}
$$

Then $W=\left[W_{1}, W_{2}, \cdots, W_{n}\right]^{T}$

4) Calculate the maximum characteristic root $\lambda_{\max }$;

$$
\lambda_{\max }=\sum_{i=1}^{n} \frac{(A W)_{i}}{n W_{i}},
$$

here, $(A W)_{i}$ is the i-th component of $A W$.

Then we calculate the consistency index:
$C I=\frac{\lambda_{\max }-n}{n-1}$. Obviously, when the matrix is of full consistency, $C I=0$. And we also need to determine the average and random index of the matrix, RI. For $1 \times 1$ to $10 \times 10$ matrix, RI is shown in Table 3 .

When $n>2$, the rate of CI to RI is called random consistency rate of judgment matrix $(\mathrm{CR}), \mathrm{CR}=\mathrm{CI} / \mathrm{RI}$.

When $C R<0.1$, the matrix is acceptable and has full consistency. Or, proper modification is essential.

\section{Weighted Comprehensive Evaluation}

The linear weighted comprehensive evaluation can be more comprehensive to evaluate the rationality of urban housing price, and can identify the priorities and weaknesses. In addition, it gives a composite index which can reflect the general information. This can make up the deficiency of statistical indicator system.

Weighted comprehensive evaluation uses the individual index standardized to multiply the corresponding weight and then add to the overall evaluation.

$$
A=\sum_{i=1}^{n} W_{i} A_{i} \times 100 \%
$$

Here, $\sum_{i=1}^{n} W_{i}=1, A$ : the rationality index of housing price, $W_{i}$ : the weight of i-index, $A_{i}$ : the rationality index of i-index.

Accordingly, $\mathrm{A} \in[0,1]$. If $A=100 \%$, the commercial housing prices are entirely reasonable; If $A=0$, the housing prices are completely unreasonable. In this article, we provides $A=60 \%$ as the critical point, that means urban commercial housing prices is basically rational in China.

Table 3. Average random consistency index $R I$.

\begin{tabular}{ccccccccccc}
\hline $\mathrm{n}$ & 1 & 2 & 3 & 4 & 5 & 6 & 7 & 8 & 9 & 10 \\
\hline$R I$ & 0 & 0 & 0.58 & 0.9 & 1.12 & 1.26 & 1.36 & 1.41 & 1.46 & 1.49 \\
\hline
\end{tabular}




\section{Conclusions}

This paper establishes the integrated evaluation model of urban commercial housing. The sorting of indexes are as follows: Ratio of commercial housing, Homeownership rate, Housing Vacancy Rate, Ratio of house Price to Income, Housing expenditure ratio, Ratio of housing price growth rate to it of income, Ratio of rent to housing price, Ratio of housing price growth rate to it of retail price, Ratio of housing price growth rate to it of GDP. On one hand, the results reflected the relative importance of the factors which affect China's commercial housing. On the other hand, it reflects we should cut down housing prices, increase income, and improve the affordability of residents of purchase currently.

\section{REFERENCES}

[1] G. F. Wen, "Observation about Housing Price," Price Theory and Practice, Vol. 4, 1998.
[2] Y. L. Zhao and H. Li, "Construction of City Housing Price System," Research about Engineering and Higher Education, Vol. 23, No. 4, 2004, pp. 11-12.

[3] R. Y. Zhu and X. M. Li, "Positive Analysis about Reasonableness of City Housing Price in the East of Our Country," China Consumption Price, Vol. 23, No. 4, 2008, pp. 11-12.

[4] D. Du and Q. H. Pang, "Comprehensive Evaluation Method and Selective Case," Tsinghua University Press, Beijing, 2005.

[5] I. Greef and R. Haas, "Housing Prices, Bank Lending, and Monetary Policy," Financial Structure, Bank Behavior and Monetary Policy in the EMU Conference, Groningen, 2000.

[6] J. R. A. Pozdena, "Testing for Bubbles in the U. S. Housing Market," University of Oregon, 2006.

[7] J. M. Quigley, "Real Estate and the Asian Crisis," Journal of Housing Economics, Vol. 10, No. 2, 2001, pp. 129161. 